\title{
Aflatoxins and Anthraquinones from Diploids of Aspergillus parasiticus
}

\author{
By J. W. BENNETT \\ Southern Regional Research Center, Science and Education Administration, \\ U.S. Department of Agriculture, New Orleans, Louisiana, 70119, U.S.A.
}

(Received 9 December 1978)

\begin{abstract}
Three spore colour, two mycelial colour and 12 auxotrophic mutants were isolated from an aflatoxigenic strain of Aspergillus parasiticus. These mutants and heterozygous diploids formed by pairwise combinations of auxotrophs were assayed for aflatoxin production; norsolorinic acid and versicolorin A production were also assayed in the diploids. In general, introduction of an auxotrophic marker lowered aflatoxin production in haploids. The green-spored, prototrophic diploids resembled haploid wild-type strains in that they produced high levels of aflatoxin, low levels of versicolorin A, and no detectable norsolorinic acid. Parasexual analysis of segregants from four heterozygous diploids was hampered by the uniform conidiospore diameter of haploids and diploids and by the non-random recovery of genotypes among somatic segregants with and without treatment with $p$-fluorophenylalanine. Nevertheless, this technique is useful for recombinational analysis of mutants blocked in aflatoxin synthesis. The fortuitous association of mycelial pigmentation with certain blocked aflatoxin mutants should prove useful in future analyses of the genetics and biosynthesis of these economically important secondary metabolites.
\end{abstract}

\section{INTRODUCTION}

Aflatoxins are a group of biologically active compounds with similar chemical structure produced by certain strains of Aspergillus flavus and Aspergillus parasiticus. Aflatoxins induce both acute and chronic toxicological effects in mammals, as well as carcinogenic, teratogenic and mutagenic effects in a wide range of test systems (Chu, 1977). Moreover, there is mounting evidence that implicates aflatoxins as the aetiological agents in some primary human liver cancers (Shank, 1977) and in Reye's Syndrome, an acute paediatric syndrome of high mortality (Bourgeoise, 1974; Hogan et al., 1978). The ubiquity of aflatoxinproducing fungi, the potent biological activity of aflatoxins at very low concentrations, and the potential medical and veterinary hazard have stimulated considerable research (see, for example, Goldblatt, 1969; Detroy et al., 1971; Roberts, 1974).

Numerous surveys of natural populations of $A$. flavus and $A$. parasiticus have shown that some isolates produce aflatoxins, while others do not. Diener \& Davis (1969) summarized many of the published reports and calculated that of 1390 strains isolated from nature, about $40 \%$ produced no detectable toxin. After a thorough taxonomic study, Hesseltine et al. (1970) concluded that most strains of $A$. parasiticus are highly toxigenic and regularly produce the four major aflatoxins $\left(\mathrm{B}_{1}, \mathrm{~B}_{2}, \mathrm{G}_{1}\right.$ and $\left.\mathrm{G}_{2}\right)$, while $A$. flavus included strains that produce low to high levels of $\mathbf{B}$ aflatoxins only and strains that produce no aflatoxin. Loss or attenuation of aflatoxigenicity by originally highly toxic strains of $A$. flavus and $A$. parasiticus has been reported after serial transfers in the laboratory on synthetic and natural substrates for mass transfers (Kulik \& Holaday, 1966; DeVogel et al., 1965), single spore isolates (Mayne et al., 1971) and after exposure to barium ions (Lee \& Townsley, 1968). 
The basis of this variable toxigenicity in natural and laboratory populations is presumably genetic, but despite the voluminous literature on aflatoxins, little is known about inheritance of aflatoxigenicity.

Because both $A$. flavus and $A$. parasiticus are imperfect, conventional genetic analysis by means of sexual crosses is not possible. However, the parasexual cycle, consisting of heterokaryosis, diploidization, and recombination via haploidization or mitotic crossingover, provides an 'alternative to sex' (Haldane, 1955) for many imperfect fungi. Evidence for the parasexual cycle has been reported in A. flavus for both a highly toxigenic strain (Papa, 1973, 1976) and a poorly toxigenic strain containing virus-like particles (Gussack et al., 1977), but attempts to form heterokaryons and diploids between auxotrophic mutants of these two A. flavus strains were unsuccessful (Gussack et al., 1977). Both Bennett (1973) and Papa (1978) have indicated that parasexual analysis is also possible for $A$. parasiticus.

Blocked mutants isolated during studies on aflatoxin biosynthesis are a potential genetic resource that has not yet been exploited. To date, there are five known intermediates in aflatoxin biosynthesis: sterigmatocystin, versiconal hemiacetal acetate, averufin, norsolorinic acid and versicolorin A (Lee et al., 1976; Singh \& Hsieh, 1977; Hsieh et al., 1976). The last three are all anthraquinone pigments accumulated by mutants impaired in aftatoxin biosynthesis. The averufin-producing mutant was derived by $N$-methyl- $N^{\prime}$-nitro- $N$ nitrosoguanidine treatment of $A$. parasiticus strain ATCC 15517 (Donkersloot et al., 1972) and the norsolorinic acid- and versicolorin A-producing mutants were derived by ultraviolet irradiation of $A$. parasiticus strain SU-1 (Lee et al., 1971, 1975).

This paper describes the isolation of spore colour and auxotrophic mutants from $A$. parasiticus strain SU-1, presents evidence for the parasexual cycle in this strain (including formal genetic analysis of four selected diploids), and gives data on the production of aflatoxins in 17 haploids, and of aflatoxins, versicolorin $A$ and norsolorinic acid in 13 diploids. The structures of aflatoxin $\mathrm{B}_{1}$, norsolorinic acid and versicolorin $\mathrm{A}$ are given in Fig. 1. A preliminary report of this work has been presented (Bennett \& Marascalco, 1978).

\section{METHODS}

Media and culture conditions. The complete medium $(\mathrm{CM})$ was potato dextrose agar plus $0.5 \%(\mathrm{w} / \mathrm{v})$ yeast extract (Difco). In some experiments $0.1 \%(\mathrm{w} / \mathrm{v}) p$-fluorophenylalanine (FPA) was added to CM. The minimal medium (MM) was Czapeck Solution Agar (Difco). Nutritional supplements were added to MM as follows $\left(\mathrm{mg} \mathrm{l}^{-1}\right)$ : lysine, cysteine, serine and arginine, 250; adenine, 20; pyridoxine, $0 \cdot 1$.

For aflatoxin assays, cultures were grown on shredded wheat as described by Mayne et al. (1971). For anthraquinone assays, the liquid defined medium (AM) devised by Adye \& Matales (1964) was used, except that it contained sucrose $\left(50 \mathrm{~g} \mathrm{l}^{-1}\right)$ instead of glucose. Shredded wheat cultures were stationary but AM cultures were shaken; both were incubated for $7 \mathrm{~d}$ at $30^{\circ} \mathrm{C}$ in the dark.

Organisms. All mutants used in this study were derived from a wild-type strain of A.parasiticus designated SU-1 (NRRL A-16,462), provided by Miss Ruth Y. Mayne of the Southern Regional Research Center, New Orleans, La, U.S.A. Wild-type SU-1 is green-spored, prototrophic, has a light-yellow mycelium and normally produces high levels of both $\mathrm{B}$ and $\mathbf{G}$ aflatoxins.

Mutations were induced in SU-1 by irradiating $20 \mathrm{ml}$ conidiospore suspensions in an open Petri dish for 2 to 8 min with a $30 \mathrm{~W}$ germicidal ultraviolet lamp (GE G30T8) at a distance of $30 \mathrm{~cm}$. Appropriate dilutions of irradiated conidia were plated on CM, and white, yellow and brown spore colour mutants were selected visually. The spore colour mutants were in turn subjected to ultraviolet irradiation, and two mycelial colour mutants were isolated as described previously (Bennett \& Goldblatt, 1973). One mycelial colour mutant was from a brown-spored mutant and produced the orange-red mycelial pigment identified as norsolorinic acid; this strain is designated br-1 nor-1 (NRRL A-17,996; ATCC 24690). The other mycelial colour mutant was from a white-spored strain and produced the bright-yellow mycelial pigment identified as versicolorin A; this strain is designated wh-1 ver-1 (1-11-105 wh-1; ATCC 36537). Auxotrophic strains were selected from irradiated spore colour mutants ( $b r-1$ nor-1 and wh-1 ver-1) by replica plating with cotton-velveteen from CM to MM. The stock culture notations of mutant strains used in this study, with their equivalent spore colour, mycelial colour, nutritional requirements and the stock number of the parasexual cross in which they were utilized, are listed in Table 1. 
<smiles>COc1cc2c(c3oc(=O)c4c(c13)CCC4=O)C1C=COC1O2</smiles>

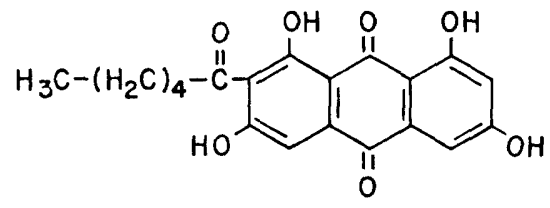

Norsolorinic acid<smiles>O=C1c2cc(O)cc(O)c2C(=O)c2c1cc1c(c2O)C2C=COC1O2</smiles>

Versicolorin A

Fig. 1. Chemical structures of aflatoxin $\mathbf{B}_{\mathbf{1}}$, norsolorinic acid and versicolorin $\mathbf{A}$.

Aflatoxin and anthraquinone assays. Aflatoxins were extracted from shredded wheat with aqueous acetone as described by Pons et al. (1966). Final extracts of aflatoxins were suspended in chloroform and appropriately diluted samples were subjected to thin-layer chromatography (t.l.c.) on Adsorbosil-1 silica gel plates in chloroform/acetone ( $95: 5$, by vol.). Aflatoxins were quantified densitometrically according to the method of Pons et al. (1968).

For norsolorinic and versicolorin A assays, mycelium was separated from the culture filtrate of AMgrown cultures by gravity filtration through cheesecloth. All pigments were in the mycelium so the culture filtrate was discarded. The mycelium was soaked overnight in acetone and then the acetone/mycelium mixture was macerated in a Waring Blender for $1 \mathrm{~min}$. The resultant slurry nas filtered through a Buchner funnel and maceration was repeated with additional acetone until the mycelium was colourless. An equal volume of water was added to the final acetone solution and this mixture was extracted twice with chloroform in a separating funnel; chloroform extracts were made to volume and assayed on Adsorbosil-1 silica gel plates by t.l.c. in benzene/acetic acid (95:5, by vol.). Norsolorinic acid and versicolorin A were estimated visually by comparing fluorescent intensities of samples of extracts with standards prepared according to Bennett et al. (1976).

Parasexual analysis. Crosses were made by mixing spores of two mutant stocks with different spore colour and nutritional markers in $2 \mathrm{ml}$ deionized water overlaying $5 \mathrm{ml} \mathrm{CM}$ in a test tube. After $48 \mathrm{~h}$ at $30^{\circ} \mathrm{C}$ in the dark, mycelial mats were removed from the water surface, blotted dry on sterile filter paper and shredded into fragments which were placed on MM. Presumptive heterokaryons were observed after 2 weeks as irregularly shaped, slow-growing colonies displaying a mixture of parental and green spore colours. The presumptive heterokaryotic cultures were flooded with sterile water and samples of the resultant dense spore suspension were plated on MM to screen for presumptive diploids. These were recognized as rapidly growing green colonies in the heterokaryotic background and confirmed by subsequent segregation of recessive gene markers. Stock cultures of diploids were subcultured from single spore isolates.

Segregants were selected by plating dilute suspensions of diploid spores on CM (controls) or CM plus FPA. Growth and sporulation were suppressed on CM plus FPA and it was difficult to distinguish rapidly growing sectors, so after 3 to $7 \mathrm{~d}$, minute colonies were transferred to CM. Segregants from both controls and FPA-treated diploids were selected on the basis of colour and appeared as small sectors bearing mutant or light-green spore colour or mutant mycelial colour markers. Only one sector of each mutant colour was selected from each diploid colony. These sectors were purified by streaking on CM; plugs of mycelium from the resultant colonies were arranged in a grid on $\mathrm{CM}$ and nutritional requirements were determined by replica plating with a multineedle inoculating device.

\section{RESULTS}

Three spore colour mutants, two mycelial colour mutants and 12 auxotrophic mutants were isolated after one to three treatments of conidiospores with ultraviolet radiation. Details of these mutants are given in Table 1 and their aflatoxin production on shredded wheat is detailed in Table 2 . In all cases, introduction of a nutritional requirement into an aflatoxigenic prototrophic strain bearing a spore colour or the norsolorinic acid marker 
Table 1. Haploid strains of Aspergillus parasiticus

\begin{tabular}{|c|c|c|c|c|}
\hline Genotype & Spore colour & Mycelial colour & $\begin{array}{l}\text { Nutritional } \\
\text { requirement }\end{array}$ & $\begin{array}{c}\text { which strain was } \\
\text { involved }\end{array}$ \\
\hline Wild-type (SU-1) & Green & Light-yellow & None & - \\
\hline$y e-1$ & Yellow & Light-yellow & None & - \\
\hline ye-1 lys-1 & Yellow & Light-yellow & Lysine & 16,19 \\
\hline ye-1 lys-4 & Yellow & Light-yellow & Lysine & 23 \\
\hline wh-1 & White & Light-yellow & None & - \\
\hline wh-1 met-1 & White & Light-yellow & Methionine & 16,20 \\
\hline wh-1 cys-1 & White & Light-yellow & Cysteine & 7 \\
\hline wh-1 $p d x-2$ & White & Light-yellow & Pyridoxine & 6 \\
\hline wh-1 ver-1 & White & Dark-yellow & None & - \\
\hline wh-1 ver-1 lys-7 & White & Dark-yellow & Lysine & 2 \\
\hline wh-1 ver-1 cys -5 & White & Dark-yellow & Cysteine & 3,9 \\
\hline wh-1 ver-1 arg-2 & White & Dark-yellow & Arginine & 4,10 \\
\hline wh-1 ver-1 ser-1 & White & Dark-yellow & Serine & 1,8 \\
\hline$b r-1$ & Brown & Light-yellow & None & - \\
\hline$b r-1 p d x-1$ & Brown & Light-yellow & Pyridoxine & $1,2,3,4$ \\
\hline$b r-1$ nor-1 & Brown & Red & None & \\
\hline br-1 nor-1 lys-5 & Brown & Red & Lysine & $6,7,8,9,10,20$ \\
\hline br-1 nor-1 ade-1 & Brown & Red & Adenine & 19,23 \\
\hline
\end{tabular}

Table 2. Aflatoxin produstion on shredded wheat by haploid strains

\begin{tabular}{|c|c|c|c|}
\hline \multirow[b]{2}{*}{ Genotype } & \multicolumn{3}{|c|}{ Aflatoxin $\left.[\mu \mathrm{g} \text { (g shredded wheat) })^{-1}\right]$} \\
\hline & $\mathbf{B}_{1}$ & $\mathrm{G}_{1}$ & Total \\
\hline Wild-type (SU-1) & 1140 & 710 & 1850 \\
\hline$y e-1$ & 303 & 199 & 502 \\
\hline$y e-1$ lys-1 & 0.9 & 1.0 & 1.9 \\
\hline$y e-1$ lys -4 & $0 \cdot 1$ & $0 \cdot 3$ & $0 \cdot 4$ \\
\hline$w h-1$ & 1400 & 890 & 2290 \\
\hline wh-1 met-1 & 75 & 35 & 110 \\
\hline wh-1 cys-1 & 444 & 234 & 678 \\
\hline$w h-1 p d x-2$ & 860 & 383 & 1243 \\
\hline wh-1 ver-1 & ND & ND & ND \\
\hline wh-1 ver-1 lys -7 & ND & ND & ND \\
\hline wh-1 ver-1 cys-5 & ND & ND & ND \\
\hline wh-1 ver-1 arg-2 & ND ${ }^{\circ}$ & ND & ND \\
\hline wh-1 ver-1 ser-1 & ND & ND & ND \\
\hline$b r-1$ & 1070 & 504 & 1574 \\
\hline$b r-1 p d x-1$ & 326 & 134 & 460 \\
\hline$b r-1$ nor-1 & 493 & 348 & 841 \\
\hline br-1 nor-1 lys-5 & 0.3 & 0.6 & 0.9 \\
\hline br-1 nor-1 ade-1 & 52 & 45 & 97 \\
\hline
\end{tabular}

resulted in lower aflatoxin production. For the lysine-requiring auxotrophs, the low aflatoxigenicity could be correlated with poor growth on shredded wheat. Supplementation with lysine (100 or $500 \mathrm{mg}$ per flask) or tryptone (500 or $1000 \mathrm{mg}$ per flask) did not improve growth. All other classes of auxotrophic mutants grew well on shredded wheat.

The 12 auxotrophic mutants were paired in 13 combinations (see Table 1, column 4). The resultant heterokaryons on MM were relatively slow-growing, irregularly shaped colonies exhibiting a mixture of the two parental spore colour markers, plus green spores, in different proportions. The green conidia were heterokaryotic [heterokaryotic conidia are possible in this species because $A$. parasiticus has multinucleate conidiospores (Yuill, 1950; Papa, 1978)]. On CM, green heterokaryotic colonies readily broke down into sectors 
Table 3. Aflatoxin and anthraquinone production by the wild-type, two mutant haploid strains and 13 diploid strains of $A$. parasiticus

\begin{tabular}{|c|c|c|c|c|c|c|}
\hline \multirow[b]{3}{*}{ Cross no. } & \multirow[b]{3}{*}{ Genotype } & \multirow{2}{*}{\multicolumn{3}{|c|}{$\begin{array}{c}\text { Aflatoxin } \\
{\left[\mu \mathrm{g}(\mathrm{g} \text { shredded wheat })^{-1}\right]}\end{array}$}} & \multicolumn{2}{|c|}{$\begin{array}{c}\text { Anthraquinone } \\
{\left[\mu \mathrm{g}(100 \mathrm{ml} \mathrm{AM})^{-1}\right]}\end{array}$} \\
\hline & & & & & \multirow{2}{*}{$\begin{array}{l}\text { Norso- } \\
\text { lorinic } \\
\text { acid }\end{array}$} & \multirow{2}{*}{$\begin{array}{l}\text { Versi- } \\
\text { colorin A }\end{array}$} \\
\hline & & $\mathbf{B}_{1}$ & $\mathrm{G}_{1}$ & Total & & \\
\hline 一 & Wild-type (SU-1) & 1140 & 710 & 1850 & ND & 60 \\
\hline$\longrightarrow$ & $b r-1$ nor-1 & 493 & 348 & 841 & 16500 & ND \\
\hline 一 & wh-1 ver-1 & ND & ND & ND & ND & 3720 \\
\hline 1 & br-1 pdx-1/wh-1 ver-1 ser-1 & 545 & 190 & 735 & ND & 100 \\
\hline 2 & $b r-1$ pdx-1/wh-1 ver-1 lys-7 & 950 & 525 & 1475 & ND & 100 \\
\hline 3 & $b r-1$ pdx-1/wh-1 ver-1 cys-5 & 605 & 320 & 925 & ND & 75 \\
\hline 4 & br-1 pdx-1/wh-1 ver-1 arg-2 & 690 & 340 & 1030 & ND & 150 \\
\hline 6 & br-1 nor-1 lys $-5 /$ wh-1 pdx-2 & 650 & 280 & 930 & ND & 150 \\
\hline 7 & br-1 nor-1 lys-5/wh-1 cys-1 & 405 & 170 & 575 & ND & 40 \\
\hline 8 & br-1 nor-1 lys-5/wh-1 ver-1 ser-1 & 515 & 200 & 715 & ND & 75 \\
\hline 9 & br-1 nor-1 lys-5/wh-1 ver-1 cys-5 & 650 & 235 & 885 & ND & 75 \\
\hline 10 & br-1 nor-1 lys-5/wh-1 ver-1 arg-2 & 530 & 235 & 765 & ND & 100 \\
\hline 16 & ye-1 lys-1/wh-1 met-1 & 895 & 415 & 1310 & ND & 100 \\
\hline 19 & ye-1 lys-1/br-1 nor-1 ade-1 & 790 & 440 & 1230 & ND & 30 \\
\hline 20 & wh-1 met-1/br-1 nor-1 lys-5 & 720 & 465 & 1185 & ND & 30 \\
\hline 23 & $y e-1$ lys-4/br-1 nor-1 ade-1 & 850 & 470 & 1320 & ND & 100 \\
\hline
\end{tabular}

ND, None detected.

of the two parental types. The frequency of heterokaryotic spores was determined by plating dilute suspensions of conidia from heterokaryons on $\mathrm{MM}$ and $\mathrm{CM}$, and ranged from 0.8 to $23.0 \%$, with certain heterokaryons consistently yielding a higher frequency. Attempts to assay heterokaryons for aflatoxigenicity were hampered by the tendency of heterokaryons to break down into one of the component strains on shredded wheat.

Diploids were isolated after plating dense suspensions of conidiospores from heterokaryons on MM. Diploids were visible as rapidly growing, green-spored colonies in the heterokaryotic background; unlike green heterokaryotic spores, diploids did not readily break down on CM. Presumptive diploids were recovered from heterokaryons at a frequency of $1.5 \times 10^{-4}$ to $7 \cdot 3 \times 10^{-3}$, with crosses displaying the highest percentage of heterokaryotic conidia also yielding the highest frequency of diploids recovered. Diploids were stable on CM, producing small sectors of mutant spore or mycelial colour at low frequency. Diploids were also stable on shredded wheat and in liquid AM.

Data on the production of aflatoxins on shredded wheat and of norsolorinic acid and versicolorin A on AM are presented in Table 3. The wild-type and the diploids produced both $\mathrm{B}$ and $\mathrm{G}$ aflatoxins. No diploid produced as much aflatoxin as did the haploid wildtype; however, with the exception of diploid 7, all diploids produced considerably more aflatoxin than did the component auxotrophs. Of particular interest are diploids 8, 9 and 10 which produced 715 to $885 \mu \mathrm{g}$ aflatoxin (g shredded wheat) ${ }^{-1}$, a striking increase in toxigenicity over the component strains.

Data on the production of norsolorinic acid and versicolorin A by the wild-type, the two blocked mutants and the 13 diploid strains are also included in Table 3 . The only strain that produced detectable norsolorinic acid was $b r-1$ nor-1, the haploid blocked mutant. Versicolorin A production was $3720 \mu \mathrm{g}(100 \mathrm{ml} \mathrm{AM})^{-1}$ for the blocked mutant wh-1 ver-1, $60 \mu \mathrm{g}(100 \mathrm{ml} \mathrm{AM})^{-1}$ for the wild-type haploid strain, and between 30 and $150 \mu \mathrm{g}(100 \mathrm{ml}$ $(A M)^{-1}$ for the 13 diploid strains. All diploid strains resembled the haploid wild-type more than the haploid component auxotrophs in that they produced high levels of aflatoxins, low levels of versicolorin A and no detectable norsolorinic acid. 
Four of the 13 diploids $(16,19,20$ and 23) were selected for parasexual analysis; diploids 19, 20 and 23 carried the norsolorinic acid marker, which is easily recognized as a brightred mycelial coloration in reverse. Unfortunately, parasexual genetic analysis is impeded in $A$. parasiticus because both haploid and diploid conidiospores are of the same diameter, which means there is no easy way to distinguish the recombinant segregants of haploidization from the diploid recombinants of mitotic crossing-over.

Segregants were selected from the four diploids on the basis of mutant spore or mycelial colour after growth on CM (controls) or CM plus FPA (Table 4). Control segregants were almost exclusively prototrophic. When the haploidization agent FPA was used in the selection of segregants, the frequency of auxotrophs increased somewhat but, except for diploid 20, the majority of segregants were prototrophic. The recovery of auxotrophic markers among FPA-treated segregants was not random, with frequencies skewed in favour of certain genotypes.

For both control and FPA-treated segregants, most of the recovered colonies were recombinant types. Among control segregants, no parental types were recovered from diploids 16, 19 and 23, and fewer than 5\% were recovered from diploid 20. With FPA treatment, the number of parental types was higher, ranging from 5 to $30 \%$.

The red mycelial colour corresponding to norsolorinic acid was introduced with the $b r-l$ spore colour gene in three of the diploids and was observed to recombine with either the $w h-1$ or ye-1 genotypes; green-spored, red-mycelial types were also recovered in each case. The frequency of red-mycelial types was low for control segregants, high for FPAtreated segregants, and was found distributed among most auxotrophic classes; however, no brown-spored, red-mycelial auxotrophs were recovered from diploid 23.

To summarize Table 4, recombination of spore colour, mycelial colour and nutritional markers was observed for each of the four diploids analysed, but certain genotypes were recovered at higher frequencies than others. These skewed frequencies from both control and FPA-treated diploids, coupled with the inability to distinguish haploid and diploid conidiospores on the basis of spore diameter, preclude conventional interpretations of these parasexual data for gene mapping.

\section{DISCUSSION}

Recombinational analysis for certain members of the Fungi Imperfecti is possible through the parasexual cycle, which consists of heterokaryosis, diploidization, and segregation via mitotic recombination or haploidization (Roper, 1966). In species with uninucleate conidia, such as Aspergillus nidulans, heterokaryotic mycelia but not heterokaryotic spores can be isolated, and haploid and diploid conidiospores can be distinguished on the basis of conidial diameter. In $A$. parasiticus, the conidiospores are multinucleate (Yuill, 1950) so both homokaryotic and heterokaryotic conidiospores are possible, and haploid and diploid conidiospores have the same diameter.

Similar problems have been encountered in parasexual analysis of another strain of A. parasiticus (Papa, 1978) and the closely related aflatoxigenic species $A$. flavus, with which Papa (1973) has had considerable success isolating haploid segregants on the basis of their rapid, uniform growth away from restricted diploid colonies on CM containing $0.007 \%$ FPA. His experiments have yielded evidence for eight linkage groups in A. flavus (Papa, $1976,1977 b$ ). In addition, he has reported a mutant of $A$. flavus that produces more aflatoxin $\mathbf{B}_{2}$ than $\mathbf{B}_{1}$ (Papa, 1977a) and found evidence for linkage between this mutant gene and the histidine locus on linkage group VIII (Papa, 1977b,c). In our experiments, three of the four diploids analysed yielded an excess of prototrophic segregants after FPA treatment, as well as non-random recovery of auxotrophic markers; although Papa (1978) observed non-random recovery of auxotrophic segregants he did not observe an excess of prototrophic genotypes after FPA treatment in A. parasiticus. McCully \& Forbes (1965) have described the use of FPA in A. nidulans. 

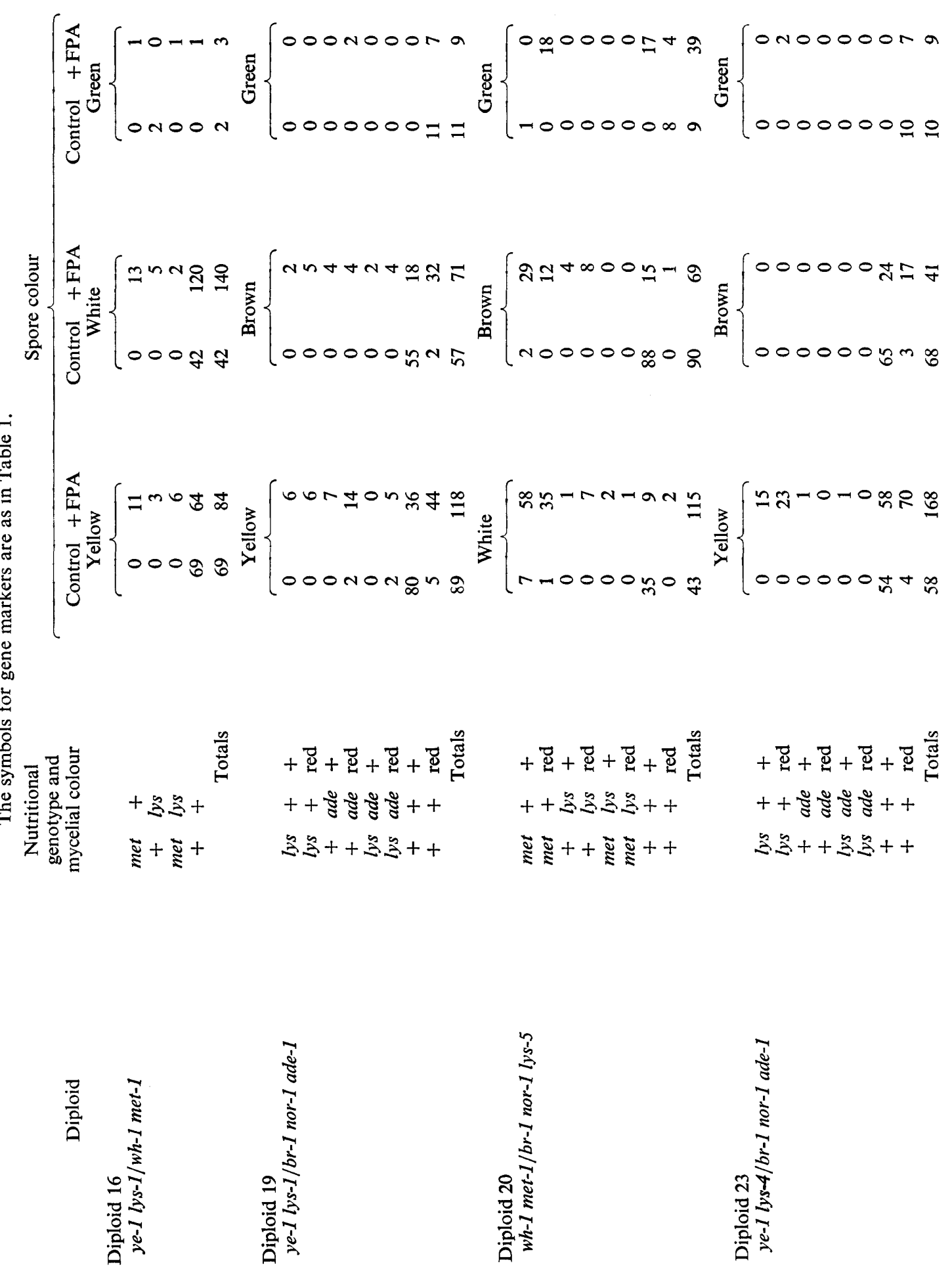
Non-random recovery of somatic segregants has been reported previously for other aspergilli including $A$. fumigatus (Stromnaes \& Garber, 1963) and A. amstelodama (Lewis \& Barron, 1964). Coy \& Tuveson (1964) have suggested that both the mutant markers and the growth medium may affect the ratio of genotypes. Our results do not permit a distinction between genetic linkage, growth medium or poor viability of certain mutants as the cause of the skewed ratios among somatic segregants. These parameters, coupled with an inability to distinguish haploid and diploid segregants by conidial diameter, will make it difficult to establish a classical linkage map in $A$. parasiticus. Nevertheless, recombinational analysis within this species may have important implications for the study of aflatoxins and other fungal secondary metabolites, even in the absence of a traditional genetic map.

Secondary metabolites, or 'idiolites' (Walker, 1974), are organic compounds of great chemical diversity, restricted taxonomic distribution and no obvious function in the metabolism of the organism that produces them. The best studied secondary metabolites are those which have demonstrated biological activity against either micro-organisms (antibiotics) or plants and animals (toxins); however, most secondary metabolites are pharmacologically inactive (Bu'Lock, 1967; Turner, 1971). Very little is known about the genetics of secondary metabolism. Most of the genetic studies conducted have concerned the introduction of mutations for strain improvement in industrially important antibioticproducing organisms (Demain, 1973). Recombinational approaches have received far less attention in industrial microbiology (MacDonald \& Holt, 1976) although new advances in plasmid technology are changing this situation for the Actinomycetes (Hopwood \& Merrick, 1977).

For the toxic and the biologically inactive secondary metabolites, even fewer genetic studies have been conducted. Here, too, the bulk of the experimentation has been mutational; examples are Gatenbeck's research on the anthraquinone pigments of Penicillium islandicum (Gatenbeck, 1965) and Gaucher's research on the biosynthesis of the mycotoxin patulin in Penicillium urticae (Sekiguchi \& Gaucher, 1978).

Because all secondary metabolites are, by definition, dispensable compounds, mutational research on secondary metabolites has been hampered by the absence of rational screening techniques based on the stringency of a conditional lethal environment (Demain, 1973). Even the vocabulary of mutational analysis in secondary metabolic systems has been impoverished; therefore, I welcome Nagaoka \& Demain's (1975) introduction of the term 'idiotroph' to describe '... mutants which grow in minimal medium but fail to produce an idiolite unless supplemented with a precursor of that secondary metabolite'.

Thus, for $A$. parasiticus, the yellow-pigmented, mutant haploid strain $w h-1$ ver- 1 can be considered an 'aflatoxin idiotroph' since it is completely blocked in aflatoxin production; however, when supplied with sterigmatocystin, an aflatoxin precursor occurring later in the pathway, aflatoxin production occurs (Singh \& Hsieh, 1977). The red-pigmented, haploid mutant strain $b r-1$ nor- 1 produces norsolorinic acid, a known aflatoxin precursor (Hsieh et al., 1976), but is not completely blocked in aflatoxin production. Perhaps by analogy to the terminology applied to auxotrophic genes, it can be termed a 'leaky idiotroph'. With one exception, all diploids isolated in this study carried either the versicolorin A marker, the norsolorinic acid marker or both. All the diploids produced high levels of aflatoxins and low levels of anthraquinone pigments, thus indicating that idiotrophy is recessive to the wild-type condition for these mutants. Since both versicolorin A and norsolorinic acid cause a mycelial pigmentation, visual screening of these idiolitic markers is possible.

As more idiotrophs become available through research on aflatoxin biosynthesis, recombinational analysis of these blocked mutants via the parasexual cycle may clarify both the genetics and the biosynthesis of aflatoxins. The fortuitous association of mycelial pigmentation with aflatoxin idiotrophy (four of the five known aflatoxin intermediates are brightly coloured anthraquinones; three of these are accumulated by blocked mutants) may make $A$. parasiticus a useful model system for genetic studies in fungal secondary metabolism. 
I wish to thank Dr L. A. Goldblatt for his support and encouragement, Dr A. L. Demain for the stimulating discussions on the use of mutations in the study of secondary metabolism and B. A. Marascalco, L. S. Lee and C. Vinnett for experimental assistance. Portions of this work were conducted during a National Research Council Agricultural Research Service Postdoctoral Research Associateship at the Southern Regional Research Center, New Orleans, Louisiana.

\section{REFERENCES}

ADYE, J. \& MATALES, R. I. (1964). Incorporation of labelled compounds into aflatoxins. Biochimica et biophysica acta 86, 418-420.

BeNNETT, J. W. (1973). A method for studying the inheritance of aflatoxin producing ability in Aspergillus flavus and A. parasiticus. Genetics 74, s20.

Bennetr, J. W. \& Goldblatt, L. A. (1973). The isolation of mutants of Aspergillus flavus and $A$. parasiticus with altered aflatoxin producing ability. Sabouraudia 11, 235-241.

Bennett, J. W. \& Marascalco, B. A. (1978). Aflatoxin and anthraquinone production by diploids of Aspergillus parasiticus. Abstracts of the Third International Symposium on the Genetics of Industrial Microorganisms p. 24.

Bennett, J. W., Lee, L. S. \& CuCullu, A. F. (1976). Effect of dichlorvos on aflatoxin and versicolorin A production in Aspergillus parasiticus. Botanical Gazette 137, 318-324.

BourgeoISE, C. H. (1974). Encephalopathy and fatty viscera: a possible response to acute aflatoxin poisoning. In Reye's Syndrome, pp. 131-145. Edited by J. D. Pollack. New York, San Francisco \& London: Grune \& Stratton.

Bu'Lock, J. D. (1967). Essays in Biosynthesis and Microbial Development. New York: John Wiley.

CHU, F.S. (1977). Mode of action of mycotoxins and related compounds. Advances in Applied Microbiology 22, 83-143.

CoY, D. O. \& Tuveson, R. W. (1964). The effects of supplementation and plating densities on apparently aberrant meiotic and mitotic segregation in Aspergillus rugulosus. Genetics 50, 847-853.

Demain, A. L. (1973). Mutation and the production of secondary metabolites. Advances in Applied Microbiology 16, 177-202.

Detroy, R. W., Lillehoj, E. B. \& Ciegler, A. (1971). Aflatoxin and related compounds. In Microbial Toxins, pp. 3-157. Edited by A. Ciegler, S. Kadis \& S. Ajl. New York: Academic Press. DeVogel, P., Van Rhee, R. \& Koelensmid, W. A. A. (1965). A rapid screening test for aflatoxin synthesizing Aspergilli of the flavus-oryzae group. Journal of Applied Bacteriology 28, 213-220.

Diener, J. L. \& DAvis, N. D. (1969). Aflatoxin formation by Aspergillus favus. In Aflatoxin. Scientific Background, Control and Implications, pp. 13-54. Edited by L. A. Goldblatt. New York: Academic Press.

Donkersloot, J. A., Matales, R. I. \& YANG, S. S. (1972). Isolation of averufin from a mutant of Aspergillus parasiticus impaired in aflatoxin biosynthesis. Biochemical and Biophysical Research Communications 47, 1051-1055.

GATENBECK, S. (1965). Studies on the basic metabolism determining the biosynthesis of malonate derived compounds in Penicillium islandicum. In Biogenesis of Antibiotic Substances, pp. 255260. Edited by Z. Vanek \& Z. Hostalek. New York: Academic Press.

GoldblatT, L. A. (editor) (1969). Aflatoxin. Scientific Background, Control and Implications. New York: Academic Press.

Gussack, G., Bennett, J. W., Cavalier, S. \& YATSU, L. (1977). Evidence for the parasexual cycle in a strain of Aspergillus flavus containing virus-like particles. Mycopathologia 61, 159-165.

Haldane, J. B. S. (1955). Some alternatives to sex. New Biology 19, 7-26.

Hesseltine, C. W., Sorenson, W. G. \& Smith, M. (1970). Taxonomic studies of the aflatoxin-producing strains in the Aspergillus flavus group. Mycologia 62, 123-132.

Hogan, G. R., Ryan, N. J. \& Hayes, A. W. (1978). Aflatoxin $B_{1}$ and Reye's Syndrome. Lancet i, 561 .

Hopwood, D. A. \& MERRICK, M. J. (1977). Genetics of antibiotic production. Bacteriological Reviews 41, 595-634.

HsIEH, D. P. H., LIN, M. T., YAO, R. C. \& SINGH, R. (1976). Biosynthesis of aflatoxins: conversion of norsolorinic acid and other hypothetical intermediates into aflatoxin $\mathrm{B}_{1}$. Journal of Agricultural and Food Chemistry 24, 1170-1174.

Kulik, M. M. \& HoladAy, C. E. (1966). Aflatoxin: a metabolic product of several fungi. $\mathrm{Myco-}$ pathologia and mycologia applicata 30, 137140.

LeE, E. G. H. \& Townsley, P. M. (1968). Chemical induction of mutation or variation in aflatoxinproducing cultures of Aspergillus flavus. Journal of Food Science 33, 420-423.

Lee, L. S., BennetT, J. W., Goldblatt, L. A. \& LundIN, R. E. (1971). Norsolorinic acid from a mutant strain of Aspergillus parasiticus. Journal of the American Oil Chemists Society 48, 93-94.

Lee, L. S., Bennett, J. W., Cucullu, A. F. \& Stanley, J. B. (1975). Synthesis of versicolorin A by a mutant strain of Aspergillus parasiticus deficient in aflatoxin production. Journal of Agricultural and Food Chemistry 23, 1132-1134.

LeE, L. S., BenNetT, J. W., Cucullu, A. F. \& ORY, R. L. (1976). Biosynthesis of aflatoxin $B_{1}$. Conversion of versicolorin $A$ to afiatoxin $B_{1}$ by $A$ spergillus parasiticus. Journal of Agricultural and Food Chemistry 24, 1167-1171.

LEWIS, L. A. \& BARron, G. L. (1964). The pattern of the parasexual cycle in Aspergillus amstelodami. Genetical Research 5, 162-163.

MCCully, K. S. \& Forbes, E. (1965). The use of $p$ fluorophenylalanine with 'master strains' of Aspergillus nidulans for assigning genes to linkage groups. Genetical Research 6, 352-359. 
MacDonald, K. D. \& HolT, G. (1976). Genetics of biosynthesis and overproduction of penicillin. Science Progress 63, 547-573.

MAYNE, R. Y., BenNETt, J. W. \& TALlant, J. (1971). Instability of an aflatoxin-producing strain of Aspergillus parasiticus. Mycologia 63, 644-648.

NaGaOKA, K. \& Demain, A. L. (1975). Mutational biosynthesis of a new antibiotic, streptomutin A, by an idiotroph of Streptomyces griseus. Journal of Antibiotics 28, 627-635.

PAPA, K. E. (1973). The parasexual cycle in Aspergillus flavus. Mycologia 65, 1201-1205.

PAPA, K. E. (1976). Linkage groups in Aspergillus flavus. Mycologia 68, 159-165.

PAPA, K. E. (1977a). Mutant of Aspergillus flavus producing more aflatoxin $\mathrm{B}_{2}$ than $\mathrm{B}_{1}$. Applied and Environmental Microbiology 33, 206.

PAPA, K. E. (1977b). Genetic analysis of a mutant of Aspergillus flavus producing more aflatoxin $\mathrm{B}_{2}$ than $\mathrm{B}_{1}$. Mycologia 69, 556-562.

PAPA, K. E. (1977c). Genetics of aflatoxin production in Aspergillus flavus: linkage between a gene for a high $\mathrm{B}_{2}: \mathrm{B}_{1}$ ratio and the histidine locus on linkage group VIII. Mycologia 69, 1185-1190.

Papa, K. E. (1978). The parasexual cycle in Aspergillus parasiticus. Mycologia 70, 766-773.

Pons, W. A., Cucullu, A. F., Franz, A. O. \& GoldBlatT, L. A. (1968). Improved objective fluorodensitometric determination of aflatoxins in cottonseed products. Journal of the American Oil Chemists Society 45, 694-699.

Pons, W. A., Cucullu, A. F., Lee, L. S., Robertson, J. A., Franz, A. O. \& Goldblatt, L. A. (1966). Determination of aflatoxins in agricultural products: use of aqueous acetone for extraction. Journal of the Association of Official Analytical Chemists 49, 554-562.

ROBERTS, J. C. (1974). Aflatoxins and sterigmatocystins. Forschritte der Chemie organischer Naturstoffe 31, 119-151.

ROPER, J. A. (1966). The parasexual cycle. In The Fungi, vol. II, pp. 589-617. Edited by G. C. Ainsworth \& A. S. Sussman. New York: Academic Press.

SEKIGUCHI, J. \& GAUCHER, G. M. (1978). Identification of phyllostine as an intermediate of the patulin pathway in Penicillium urticae. Biochemistry 17, 1785-1791.

SHANK, R. D. (1977). Epidemiology of aflatoxin carcinogenesis. Advances in Modern Toxicology 3, 291-318.

Singh, R. \& HSIEH, D. P. H. (1977). Aflatoxin biosynthetic pathway: elucidation by using blocked mutants of Aspergillus parasiticus. Archives of Biochemistry and Biophysics 178, 285-292.

Stromnaes, O. \& Garber, E. D. (1963). Heterocaryosis and the parasexual cycle in Aspergillus fumigatus. Genetics 48, 653-662.

TURNER, W. B. (1971). Fungal Metabolites. New York: Academic Press.

WALKER, J. B. (1974). Biosynthesis of the monoguanidinated inositol moiety of bluensomycin, a possible evolutionary precursor of streptomycin. Journal of Biological Chemistry 249, 2397-2404.

YUILL, E. (1950). The numbers of nuclei in conidia of Aspergilli. Transactions of the British Mycological Society 33, 324-333. 